workers reported that certain species of humble bee had now been kept in domestication for several years, and this had enabled a much more detailed investigation of their breeding habits than had formerly been possible.

The use of 'scent direction' to improve the value of honey bees as pollinators was discussed by several contributors, but results had been somewhat varied, and it was evident that further work on this important subject is needed. Attention was directed to the varying composition of nectar between the different plant species, and the possibility that this might influence pollination was discussed. The pollination of lucerne, the subject of another session, was covered by papers describing work on this subject in North America.

At the closing session of the symposium, the following conclusions were agreed.

(1) An annual census of bumble bees would be desirable in order to identify trends in populations that could be associated with changing agricultural practices.

(2) Solution of the seed production problem in tetraploid red clover will require continued effort by plant breeders, pollination specialists and biologists.

(3) Greater effort should be given to obtaining a better understanding of the basic relationship between pollinators and flower. Identification of morphological or physiological links in those species of bees having a restricted host-range would be worth while.
(4) Pollination should be considered as one of a number of factors, and consideration should be given to them all when studying seed production. Increased effort should be given to domestication of bumble-bees. However, much more basic informa. tion needs to be developed before the full potential of this endeavour can be realized.

(5) Exchange of pollinators between countries should be oncouraged. An effort should be made to provide the proper pollinator for a given crop. This can be done by growing the crop where pollination occurs naturally, or by providing the pollinator where it does not occur naturally. A survey of all known pollinating insects for clover and alfalfa is required.

(6) Honey bees should be exploited to the maximum extent possible. Information concerning this pollinator is greater than for any of the others, and should be utilized.

(7) Scent training should be studied further; but identification of the volatile products in flowers would seem to be necessary in order to advance this phase of the work.

These recommendations, with the papers read at the symposium, are to be published in due course. The secretary of the symposium was Dr. Ole Hammer, assisted by Dr. Tom Mittler, Statens Biavlsforsøg, Strødam, Hillerød, Denmark.

R. P. Hawkins

M. S. Percival

\title{
GENERATION AND APPLICATION OF ELECTROSTATIC POWER
}

\begin{abstract}
$\mathrm{A}^{\mathrm{N}}$ $\mathrm{N}$ international colloquium, held under the auspices of the Centre National de la Recherche Scientifique, was held at Grenoble during September 24 -October 1 . The subjects discussed covered the generation of electrical power by electrostatic means and the applications of these machines. It is believed to have been the first international conference devoted entirely to the science of electrostatics. Due to the presence of Prof. N. J. Felici, who is the holder of the chair of olectrostatics at the University of Grenoble, this was a natural meeting place, and more than 120 engineers and physicists gathered there.

Appropriately, after a description of the early days of electrostatic machines in Grenoble, given by Prof. L. Néel, the lectures were inaugurated by Prof. Felici's discussion of the types of electrostatic generator and his hopes for the next 'generation' of electrostatic machines. This, in conjunction with a talk by Prof. J. G. Trump of the Massachusetts Institute of Technology, indicated in broad outline the scope of present possibilities and the problems of the future. There were two types of electrostatic generator in current use: first, the Van de Graaff belt-type machine, and secondly, the Felici insulating transporter cylindrical machine. Both have their advantages and disadvantages. Briefly, for high voltages and very low currents the Van de Graaff is better, and for low voltages (below one million volts) and higher currents (up to $50 \mathrm{~m}$.amp.) the Felici machines are better. For long-term continuous running, the cylinder machine is undoubtedly more reliable, but in its present state of development it cannot provide the very high voltages or current
\end{abstract}

that may be required. Prof. Trump discussed also a further type of electrostatic generator, the disk machine. This is by no means a new development, and on show at the colloquium was a very early disk-type generator built in the late 1940's at Grenoble. However, it seems to be generally agreed that this type of design has the greatest development possibilities, particularly for space travel, where the problem of insulation is much reduced.

Several papers were presented which discussed the application of this type of electrostatic generator for ion propulsion. Considerable research is being carried out both in France and the United States on electrostatic machines for this purpose. The design of a generator delivering $1,250 \mathrm{~kW}$. at $200 \mathrm{kV}$. is being investigated at the High Voltage Engineoring Corporation in Massachusetts. Parallel work is proceeding in France.

The future development of the cylinder machine is being investigated to increase the currents available, and other dielectrics, including various liquids, are being studied. Questioning elicited visualized requirements in the region from $100 \mathrm{kV}$. at 100 m.amp. to $1 \mathrm{MeV}$. at $1 \mathrm{amp}$, but no concrete suggestions as to how this might be achieved were agreed. The emphasis on ion engines for space travel was supplemented by a talk on eloctrohydrodynamic energy conversion by a representative of the U.S. Air Force.

Engineers who have been involved in the practical problems of designing the Felici generators and producing a standard range of models for industry gave a fascinating insight into the complexities of electrostatics as opposed to the comparative simplicity 
of electromagnetic machines, despite the duality which exists between them. There is no doubt that the shortage of technology on this subject is retarding the advance of the electrostatic machines. Nevertheless, an impressive array of standard machines were described, and on a subsequent visit to the factory of Société Anonyme de Machines Électrostatiques in Grenoble the members of the colloquium were able to see the ideas of Prof. Felici in concrete form. From the smallest machines for electrostatic deposition of paint to the large $600-\mathrm{kV}$. and $\mathrm{I}-\mathrm{MeV}$. generators for accelerators and other nuclear applications, one cannot help but be impressed by the progress of this technique. When it is realized that the continuous operation of these generators for thousands of hours with negligible maintenance is regarded as commonplace, an appreciation of the status of the technique is possible.

Of particular interest on the nuclear side were the neutron generators capable of delivering fluxes of neutrons up to $10^{11}$ neutrons per sec. Continuous development aimed at greater fluxes with smaller machines is being carried out.

To sum up, the position of the electrostatic generators at the present time is not easy. Both the French and American experts expressed faith that the present machines are the first in a field capable of great development. Discussion gave glimpses of actual development models in course of construction at the present time. Whether certain fundamental difficulties will obstruct this advance or whether new techniques will emerge remains to be seen. What. ever happens, great resources of money and labour will have to be made available.

The remainder of the lectures dealt with the applications of electrostatic machines. Two very interesting papers were read, one by Dr. W. D. Allen (Atomic Energy Research Establishment, Harwell) and the other by Mr. F. A. Julian (Atomic Weapons Research Establishment, Aldermaston). They described the remarkable achievements of the staff of the United Kingdom Atomic Energy Authority in constructing two $12 \mathrm{MeV}$. tandem accelerators which have now been in operation for the past year. The many problems which they encountered and overcame were discussed and a résumé of the experimental work carried out, both in the design of the machines and their subsequent usage, were given.
In the more commercial field of precipitation and mineral separation, the use of electrostatic generators has, as yet, had little application apart from the deposition of paint. Demonstrations of the paint precipitation plant show the fascinating possibilities of electrostatic machines in industry. The $100-\mathrm{kV}$. unit is very small, approximately $24 \mathrm{in}$. long, $9 \mathrm{in}$. wide and $9 \mathrm{in.} \mathrm{high,} \mathrm{and} \mathrm{completely} \mathrm{safe.} \mathrm{The} \mathrm{operator}$ may place his finger on the high-voltage terminal of the spray gun and feel very little effect. The generator is very light and easily portable. Being sealed in a high-pressure cylinder, it is impervious to all dirt and damp.

For other heavier precipitation processes, the electrostatic machine, so far, does not yet deliver sufficient current. Considerable research is going on in the United States in mineral separation. and, in Europe, on insecticidal spraying in agriculture.

Future applications in the nuclear field would appear to lie with neutron sources of higher fluxes than at present available. If fluxes of the order of $10^{12}-10^{14}$ neutrons per sec. could be produced economically, there would be a demand from those at present forced to use reactors for activation experiments. There is some argument as to what an economic figure might be, but there is a real hope that for an accelerator working at, say, $1 \mathrm{MeV}$., $4 \mathrm{~m}$.amp. of ions in the beam of a beryllium target could produce a flux of $10^{12}$ neutrons per sec. From preliminary inspection it was severally agreed that the price of such a machine might be very attractive vis-à-vis a small reactor. A $1-\mathrm{MeV}$. accelerator and a highcurrent ion-source of this type was shown to the members of the colloquium.

Both Prof. Trump and Prof. Felici touched on the possibility of power generation by electrostatic means. It may seem inconceivable that the electromagnetic power generators could be superseded by electrostatic methods for the generation of electric power for the grid system. However, a strong plea by Prof. Felici for research funds to be made available throughout the world for work in this direction was made. Prof. Felici cited the considerable advances achieved so far in the U.S.S.R., and the United States. Perhaps the domination of the present technology has blinded engineers to the possibilities in this other field.

\section{BRITISH BOOKS AND PERIODICALS FOR USE OVERSEAS}

$\mathrm{N}$ a written answer to questions in the House of Commons on November 7 about Government Information Services, the Chancellor of the Duchy of Lancaster, Dr. C. Hill, made a long statement about the low-priced book scheme. The first group of 23 text-books on scientific, engineering and other technological subjects, he said, is now being produced, and the books should be available during the forthcoming buying season to students and others in India at $9 s, 12 s$. or $15 s$. a volume, depending on size, diagrams, illustrations, otc. It was expected to discuss shortly with the Pakistan authorities the possibility of operating a similar scheme for that country.

Dr. Hill gave a list of the titles which had been approved by the Advisory Committee, following consultation with the university authorities in India. The list involved more than 100,000 volumes and more copies would be produced as necessary. A further group of university text-books on these and other subjects would follow. The Advisory Committee has also recornmended further categories of books, similarly aimed at helping to meet tho needs of readers in developing countries in Asia and Africa. One group of titles included would help people in these countries who wished to develop their knowledge of English, or to oxtend their practical skills, and those volumes would be available in substantially larger numbers and at much lower prices than the university text-books. The Advisory Committeo recognizes that some of its other recommendations involve books which need bringing up to date or 